\section{Technology Transfer at} the EPFL

André Catana and Hervé Lebret, EPFL Industry Relation Office, Lausanne, Switzerland

$T$ echnology Transfer has become a new "buzz word" in the academic world. Everywhere in Europe, research institutions look at their American counterparts with envy or respect. Stanford University is known to generate about $\$ 40 \mathrm{M}$ per year in royalties from its Office of Technology Licensing [1], but MIT, Columbia, Caltech, Harvard and many others also generate significant revenues through licensing of their technology [2]. With the exception of the UK universities, Europe is far behind in royalty generation. Cambridge, Oxford mention figures of a few million dollars per year; on the continent, most universities do not publish any number. The figures 1 and 2 show some key data on technology transfer at the Ecole Polytechnique Fédérale de Lausanne (EPFL), including the yearly number of inventions, patents, licenses and start-ups created.

It is however worth demystifying Technology Transfer: as the Stanford revenues show, royalties will never be able to replace the traditional funding of research ${ }^{1}$. Even the growing role of industry in the funding of research is no guarantee of the success of technology transfer. So this new fame has to have other roots. As Prof. Aebischer, President of EPFL said: "Which researcher would not be satisfied to see the results of his research used for the wellbeing of the society?" [3] If the goals of research are first to explore new frontiers, it has become clear that its industrial applications have recently contributed as much to the fame of the inventors. And when they become founders of successful start-ups, these inventors are sometimes more famous than Nobel Prize winners

${ }^{1}$ Whereas royalty generation at Stanford University is in the tens of millions of dollars, its overall budget is around two billion dollars and sponsored research (e.g. through corporations and agencies such as NSF, NIH, Darpa) are in the hundreds of millions of dollars. in their university. It would not be surprising if Stanford students know more about Jerry Yang, Larry Page or Mark Horowitz than Robert Laughlin or Martin Perl.

Even if we will not see for a long time the hundred of start-ups being funded every year in the late nineties, it seems the entrepreneur mindset finally exists in Europe. It will certainly take years, maybe decades before we catch up with the US but the important element is that some early success stories will push academics with business or entrepreneurial vocations to try to catch up. It does not mean every person in academia should try and even in the US, the academic entrepreneur remains a very rare species and it should remain so.

Whereas many universities in Europe do not have and even do not wish to have technology transfer offices, EPFL launched its first effort more than ten years ago. The well-known Graetzel photovoltaic cells have been already talked about a lot and are among the most promising EPFL technologies being licensed, but the reader may be surprised that the computer mouse sold by Logitech was also developed at EPFL [4]. They should not be considered as exceptions. More than one hundred technologies have been licensed in the last couple of years. The EPFL scientific park [5] counts more than 60 young start-ups (figure 3).

One element which is seldom mentioned in technology licensing is the role of inventors in enabling a technology transfer. Very seldom will an established company be interested in a technology if it cannot collaborate with the research team which developed it. Very seldom will a start-up be created if the inventor, either a professor or a student, is not involved in the company creation.

In late 2000, Eli Kapon, a professor of Physics at EPFL travelled all over Europe to convince investors to back his project of creating a start-up to develop long wavelength VCSELs. After a few months of discussions, BeamExpress was founded in July 2001 with $\$ 3.75 \mathrm{M}$. A team of six EPFL scientists moved to the start-up and further developed the technology. In mid 2003, the company raised another $\$ 7.5 \mathrm{M}$. Eli is still a scientific consultant with the company even if he has kept his position as a professor at EPFL and the founding team of scientists is still on board.

If the team is a crucial element, time is another. There was a very strange period, in the late 90 's, certainly unique in the business world, when a company could be created in a few days, raise tens of millions of dollars in a few months and go public less

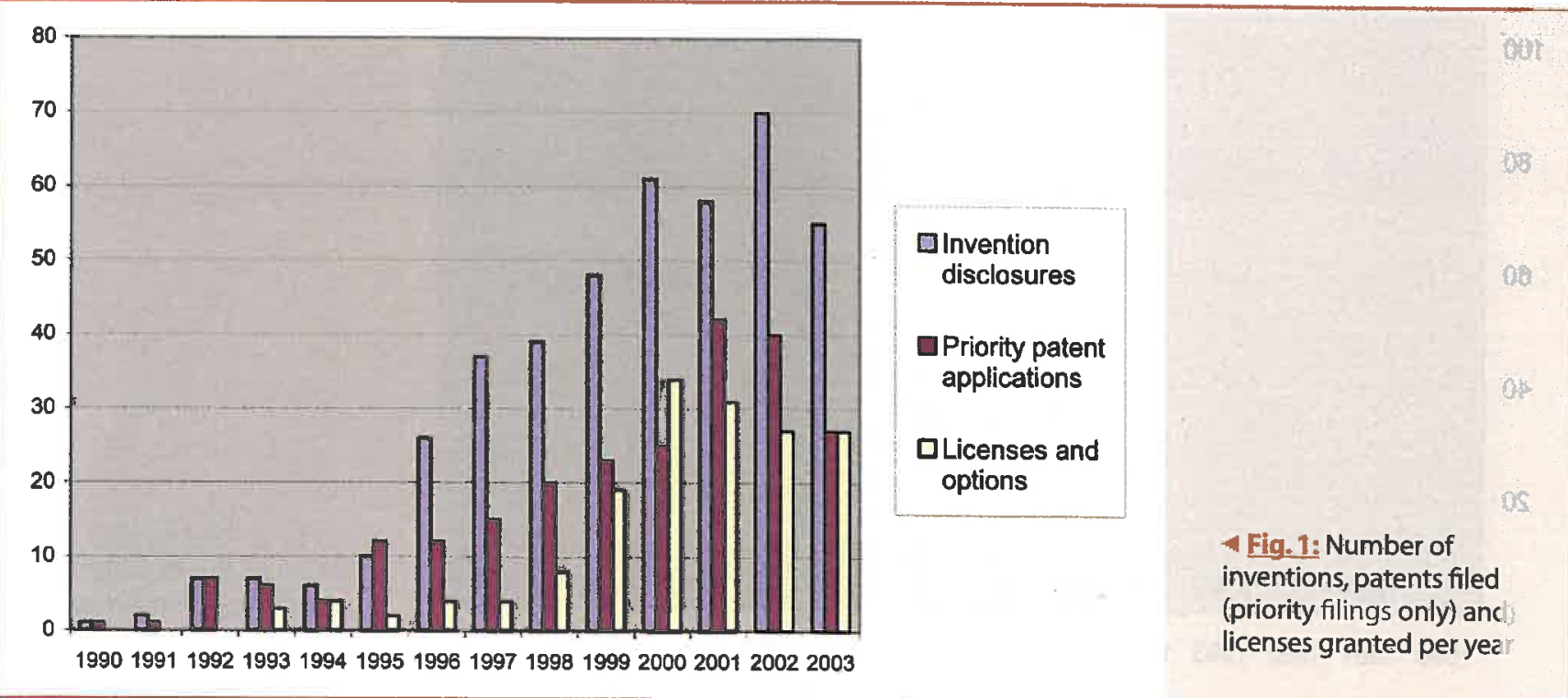


than two years after its creation. Needless to say most of these companies do not exist anymore. BeamExpress will not go public next month as it takes time from the creation of a company to its first revenues, it takes time to build a full organization, it takes time to transform a technology into products sold to customers.

It also takes time just to create a company. Pierre Fazan, a professor in the Electronics Lab of EPFL became famous in late 2001 when the semiconductor community heard about his invention of a single transistor, capacitor-less DRAM (Dynamic Random Access Memory). Like Eli, he met with venture capitalists in 2002, again in 2003. He had to explain his technology, but also its benefits, its applications, the market and who would be his customers. He had to show he had a sound intellectual property through patents filed by the Industry Relations Office of EPFL. Finally, he raised $\$ 6 \mathrm{M}$ for Innovative Silicon in late 2003 when the start-ups "shooting stars" had disappeared, when too many people complained about the difficulty of creating a start-up. The situation is just as it was before the "bubble years": it will always be challenging to be an entrepreneur, but one with a serious and sound project will be funded if he believes in it enough to convince partners. Pierre is now the CEO of Innovative Silicon and his research team has followed him in the adventure.

Neither BeamExpress nor Innovative Silicon are guaranteed successes. The path to glory, either being acquired by a bigger company for a nice amount of money or staying as a profitable standalone company like Logitech, is a very long one. Venture capitalists will tell you it takes five to seven years to build a successful company.

Whereas Innovative Silicon and BeamExpress are venture capital driven start-ups, there are others where the founders decide to preserve independence from venture capital and to follow a more conventional "organic" growth. Naturally, this can only happen when alternative ways to capital or to early stage earnings are available. Family and friends, business angels or bank loans could be such capital providers whereas earnings could be generated by early clients or licensees.

A continual search for opportunities and a strong ability to convince are absolute skills of a young entrepreneur. Hubert Lorenz, the founder and CEO of Mimotec SA would certainly not deny that. In 1996, while he was working on his $\mathrm{PhD}$ at EPFL on a novel micro-moulding technology, he met Victor Bruzzo, the manager of Indtec, one of the leading companies for the production of components for the watch industry. Victor strongly encouraged Hubert to start his own business. Two years later, Hubert and his friend Nicolas Fahrni, founded Mimotec SA to exploit the technology they developed at EPFL: "we invested all our money and also asked the families to contribute; 200,000 Swiss francs could be raised this way". Matching funds from a business angel and from Indtec's Victor Bruzzo helped double the founders' contribution and allowed the company to lift off the ground. But Mimotec's take off would not have been successful without obtaining from EPFL the transfer of intellectual property rights on the patent that was protecting the technology developed by Hubert during his thesis and without Indtec, the first client. Indeed, for the first 18 months, Indtec was covering about $90 \%$ of Mimotec's orders. So, Hubert got the "big five" ingredients for the successful launch of a start-up: novel technology, intellectual property rights, seed money, team and first client. He has no regret refusing offers from investors. "At the time when our turn-over was hardly reaching one million Swiss francs, some investors were proposing to invest up to 10 million Swiss francs in the company" says Hubert. In 2003, Mimotec had 15 employees and its turn-over reached about 3 million Swiss francs. Next step: enhancing the market extension beyond the watch market and developing the business in the US.

Having early clients is one means that helps to succeed without venture capital, and Mimotec is a nice example; another way is early licensing. And this is the way that Diagnoswiss' Fréderic Reymond and Joël Rossier followed. Diagnoswiss SA is a life science company founded by Fréderic and Joël in 1999 to develop a new generation of biochips that integrate novel methodologies for high-throughput protein analysis. These are essential for the diagnostic and drug discovery markets, and in particular for the fast growing fields of genomics and proteomics. Being active in such an emerging field without clear major players creates a large number of business opportunities for Diagnoswiss. The business idea is quite simple: acquiring and developing patented technologies and devices, bridging the gap between laboratory demonstrations and industrial prototypes, validating the use of novel technologies, developing partnerships and licensing or sublicensing intellectual property rights in well-defined market segments so as to finance proprietary development, and commercialisation of

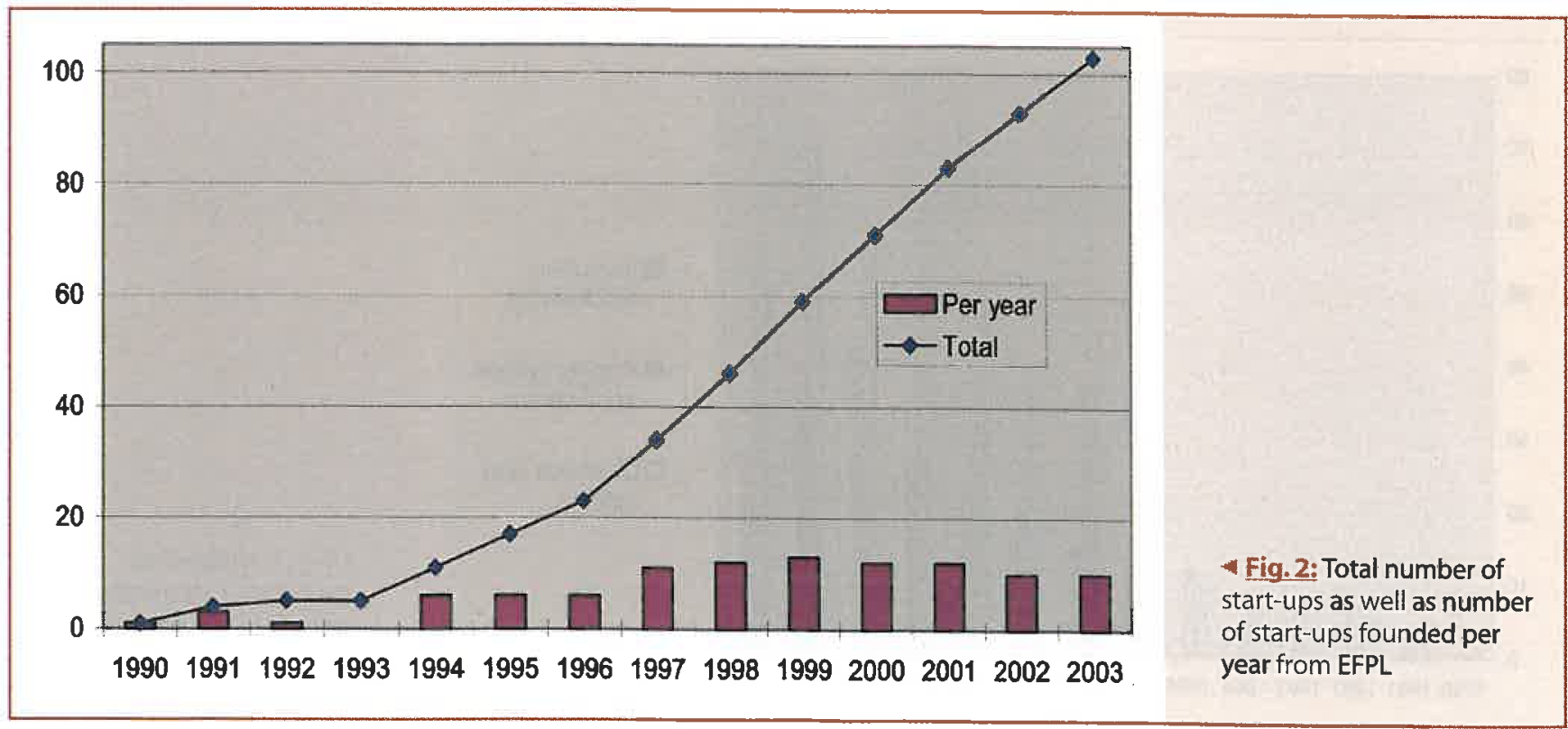


Fig. 3: The campus of the Swiss Federal Institute of Technology in Lausanne (EPFL) with its scientific park (PSE) on the right.

the company's technology in other segments. So, the company developed a strong patent portfolio largely based on technologies developed by the founders during their PhDs at EPFL. These technologies have been exclusively licensed by EPFL to the company. Among them is the so called Off-Gel electrophoresis which is expected to lead to high performance protein fractionation and purification. In 2001, Diagnoswiss entered into a collaboration and license agreement with Agilent Technologies Inc. to further develop this technology.

There are other ways to transfer technology. Creating a company may simply not be realistic when the technology is only a small brick of a much bigger system. Or the team may not have the entrepreneurial mindset and once again, there is nothing wrong with that. Licensing the technology to an established company is another option. Coming back to the Graetzel cells [6], EPFL has an interesting example of a multi-license model. More than $10 \mathrm{com}$ panies based in Europe, in the United States, in Japan and in Australia have licensed the technology and are working with EPFL's Laboratory of Photonics and Interfaces (LPI) to put the technology into production. A lot of work remains to be done, but without the collaboration between industry and EPFL, the technology would not have been developed to the current stage.

Collaborative research with industry is another rich ground for innovation and enhances the development of technologies issued from universities and their transformation into products. EPFL has had from its very first years strong links with industry and is actively promoting such interactions. It is within such an industrial collaboration founded by the Swedish chemical company Perstorp AB that Prof. Jan-Anders Manson and Louis Boogh from EPFL developed uniquely high surface interactions between hyper-branched polymers and their surrounding materials, which allows the tailoring of their properties for a large variety of applications. A real breakthrough! Perstorp extended this one year long exploratory project for three more years which brought to the lab about 1.5 million Swiss francs. The company filed several patents on the results of this work and set up a manufacturing infrastructure shortly after the end of the project. Perstorp is now one of the leading companies worldwide for the manufacture of hyper-branched polymers on a large scale and EPFL is proud to have contributed to it. But not only that: the knowledge generated within this collaboration helped the Laboratory of Composite and Polymer Technology of EPFL to become the world leading laboratory in macro-molecular engineering based on hyperbranched polymers for use in functional and structural applications; at the same time it greatly increased its attractiveness for industrial collaborations in this field.

Technology transfer is multiform. Start-ups have been the favourite model in recent years, but direct licensing with established companies or collaborative research with industry are other clear options. There are however at least two common points in any transfer: first it takes time, a long time, often much longer than what was originally envisaged and many inventors will tell you they may not have jumped into the adventure if they had known it. Second, it takes a high involvement of the inventors without whom a successful collaboration between the industry and the university is very unlikely. But all inventors will tell you that they will never regret the experience they have gained from taking the risk.

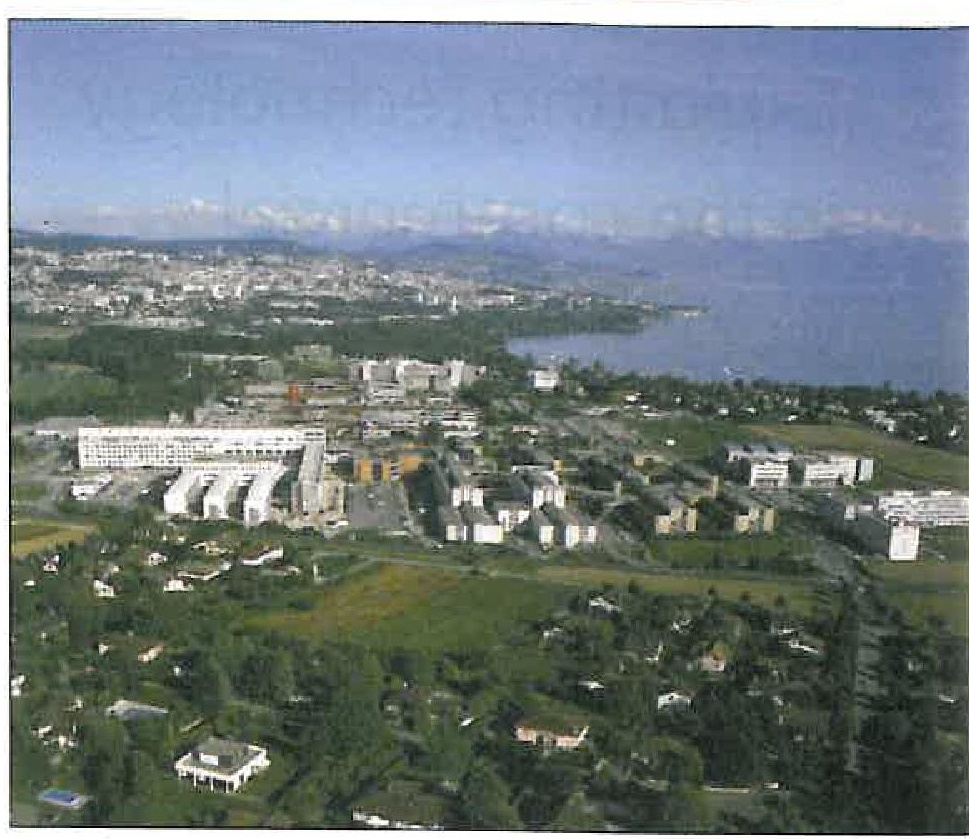

\section{About the author}

André Catana graduated from the Swiss Federal Institute of Technology, Zürich (electrical engineering) in 1985 and obtained a $\mathrm{PhD}$ in the field of semiconductor physics at EPFL in 1990. He worked for two years at IBM Research Laboratory in Rüschlikon in the field of laser science and superconductors before joining EPFL in 1992 where, he strongly contributed to the creation and development of EPFL technology transfer office and manages many of the EPFL inventions, patents and licenses

Hervé Lebret graduated from Ecole Polytechnique (France) in 1987, SupAero (Toulouse) in 1989 and obtained an MS from Stanford University in 1990, then his $\mathrm{PhD}$ in electrical engineering from Université de Rennes in 1994. In 1997, he left academics to begin a career in venture capital at Index Ventures in Geneva where he invested in Information Technology start-ups in Europe, Israel and the United States. He joined EPFL in 2004.

\section{References}

[1] Office of Technology Licensing, Stanford University, http://otl.stanford.edu

[2] Association of University Technology Managers, http://www.autm.net

[3] Les brevets biotechnologiques, PharmaCH, Juin 1997 http://www.interpharma.ch/info/wissens/pharma_ch/zeitung/f/pdf/ 97_03_f.pdf

[4] Behind the Scenes of Invention, Jean Jacques Paltenghi October 2000.

[5] Parc Scientifique de l'EPFL, http://psewww.epfl.ch

[6] Dye-Sensitized Solar Cells, Science, May 2003 http://isic.epfl.ch/load/science_gratzel.pdf 